\title{
Endoscopic treatment of obesity
}

\author{
Agnieszka Swidnicka-Siergiejko MD, Eugeniusz Wróblewski MD PhD, Andrzej Dabrowski MD
}

\section{A Swidnicka-Siergiejko, E Wróblewski, A Dabrowski. Endoscopic treatment of obesity. Can J Gastroenterol $2011 ; 25(11): 627-633$.}

BACKGROUND: The increasing incidence of obesity and overweight among children and adolescents will be reflected by the imminent increase in the number of obese patients who require more definitive methods of treatment. There is great interest in new, safe, simple, nonsurgical procedures for weight loss.

OBJECTIVE: To provide an overview of new endoscopic methods for the treatment of obesity.

METHODS: An English-language literature search on endoscopic interventions, endoscopically placed devices and patient safety was performed in the MEDLINE and Cochrane Library databases.

RESULTS: The literature search yielded the following weight loss methods: space-occupying devices (widely used), gastric capacity reduction, modifying gastric motor function and malabsorptive procedures. A commercially available intragastric balloon was the most commonly used device for weight loss. In specific subgroups of patients, it improved quality of life, decreased comorbidities and served as a bridge to surgery. More evidence regarding the potential benefits and safety of other commercially available intragastric balloons is needed to clarify whether they are superior to the most commonly used one. Moreover, early experiences with transoral gastroplasty, the duodenaljejunal bypass sleeve and an adjustable, totally implantable intragastric prosthesis, indicate that they may be viable options for obesity treatment. Other agents, such as botulinum toxin and a device known as the 'butterfly', are currently at the experimental stage.

CONCLUSION: New endoscopic methods for weight loss may be valuable in the treatment of obesity; however, more clinical experience and technical improvements are necessary before implementing their widespread use.

Key Words: Endoscopy, Gastric balloon; Obesity

$\mathrm{O}$ besity is a multifactorial, chronic disease associated with a pathoogical increase in the level of adiposity, which leads to functional impairment and increases in morbidity and mortality rates (1). Increases in the prevalence of overweight and obesity both among adults and children have been observed in many countries around the world. During the past three decades in the United States (US), overweight and obesity have reached epidemic proportions, and has become a major public health problem. Between 1980 and 2002, the prevalence of obesity in adults (older than 20 years of age) doubled, whereas the prevalence of overweight in children and adolescents (six to 19 years of age) tripled. Of special concern is the increasing incidence of obesity and overweight among children and adolescents (2). Using measured heights and weights, results from the 2005/2006 National Health and Nutrition Examination Survey (NHANES) (3) indicated that an estimated $32.7 \%$ of US adults 20 years of age or older were overweight, $34.3 \%$ were obese and $5.9 \%$ were extremely obese. In 1998, the WHO recognized obesity as a chronic disease with serious health effects and associated with the development of hypertension, ischemic disease, brain stroke, metabolic disorders (eg, type 2 diabetes and hyperlipidemia), obstructive sleep apnea, arthrosis, polycystic ovary syndromes and certain forms of cancer including esophageal and colon

\section{Le traitement endoscopique de l'obésité}

HISTORIQUE : L'incidence croissante d'obésité et d'embonpoint chez les enfants et les adolescents sera reflétée par l'augmentation imminente de patients obèses qui ont besoin de modes de traitement plus radicaux. On observe un grand intérêt envers les nouvelles interventions non chirurgicales sécuritaires et simples pour perdre du poids.

OBJECTIF : Fournir un aperçu des nouvelles méthodes endoscopiques du traitement de l'obésité.

MÉTHODOLOGIE : Les chercheurs ont effectué une recherche bibliographique en anglais dans les bases de données de MEDLINE et de la Bibliothèque Cochrane sur les interventions endoscopiques, les dispositifs implantés par voie endoscopique et la sécurité des patients. RÉSULTATS : La recherche bibliographique a permis de retracer les méthodes de perte de poids suivantes : les dispositifs qui occupent de l'espace (largement utilisés), la réduction de la capacité gastrique, la modification de la fonction motrice gastrique et les interventions de malabsorption. Le dispositif le plus utilisé pour perdre du poids était un ballonnet intragastrique offert sur le marché. Dans des sous-groupes précis de patients, ce dispositif améliorait la qualité de vie, réduisait les comorbidités et servait de passerelle en attendant l'opération. Plus de données probantes s'imposent sur les avantages potentiels et la sécurité d'autres ballonnets intragastriques offerts sur le marché pour déterminer clairement s'ils sont supérieurs à celui qui est le plus utilisé. De plus, les premières expériences de la gastroplastie transorale, du manchon de pontage gastrique duodéno-jéjunal et de la prothèse intragastrique entièrement implantable indiquent que ces interventions pourraient constituer des traitements viables de l'obésité. D'autres agents, tels que la toxine botulique et un dispositif connu sous le nom de "papillon », en sont à l'étape expérimentale.

CONCLUSION : Les nouvelles méthodes endoscopiques de perte de poids peuvent être précieuses pour traiter l'obésité. Cependant, il faudra accumuler plus d'expérience clinique et procéder à des améliorations techniques avant d'en faire une utilisation généralisée.

adenocarcinoma (4). Globally, up to 2.5 million people die every year from obesity and its complicatons. Observations of the epidemiology of obesity and its complications suggest that in Poland, the problem of obesity will soon reach epidemic proportions. Therefore, the treatment of obesity, which remains a difficult clinical problem, is very important. Initial weight loss is easily achieved, however, the maintenance of healthy weight is achieved in only $20 \%$ of patients and, only for a few years. Moreover, most obese individuals want to achieve the desired effect of losing weight as soon as possible.

The management and treatment of obesity is complex. A large number of specialists is needed to support health care in obese patients, especially endocrinologists, dieticians, gastroenterologists, surgeons, psychologists and psychiatrists. The accepted treatment methods of obesity include the following: diet modification, physical exercise, changing lifestyle and eating habits, pharmacological treatment, surgery and endoscopic treatment. The most physiological method of treatment is diet modification; however, the beneficial effect is difficult to obtain. Behavioural therapy, which includes changing lifestyle and eating habits, plays a role in supporting longterm results in all obese patients, independent of the treatment method used. Pharmacological treatment options (eg, sibutramine

Department of Gastroenterology and Internal Medicine, Medical University of Bialystok, Bialystok, Poland

Correspondence: Dr Agnieszka Swidnicka-Siergiejko, Department of Gastroenterology and Internal Medicine, Medical University of Bialystok, Ul. M.

Sklodowskiej-Curie 24a, 15-276 Bialystok, Poland. Telephone 48-85-746-8234, fax 48-85-746-8506, e-mail agnkatswidnicka@op.pl

Received for publication October 16, 2010. Accepted October 19, 2010 


\section{TABLE 1}

Methods of bariatric endotherapy

Space-occupying devices
Balloons
Bezoars
Gastric capacity reduction
Suturing - plication/partition
Modifying gastric motor function
Injections/implantations
Malabsorptive methods
Gastrojejunostomy
Bypass

and orlistat) are limited and, unfortunately, are associated with complications and contraindications. The National Institutes of Health has recommended weight loss surgery as an appropriate alternative in carefully selected individuals with severe obesity (body mass index [BMI] of $40 \mathrm{~kg} / \mathrm{m}^{2}$ or greater, or a BMI of $35 \mathrm{~kg} / \mathrm{m}^{2}$ or greater with serious comorbid conditions) when diet, behavioural and pharmacotherapy interventions fail (5-7). The number of weight loss surgeries performed in the US markedly increased from 13,365 in 1998, to 102,794 in 2003 (8). Early bariatric surgical techniques (eg, jejunoileal bypass) are no longer used given the serious complications such as vitamin deficiencies, steatohepatitis and liver cirrhosis (9). Within the past few years, various surgical procedures, including malabsorptive restrictive procedures or a combination of both, have been developed. The most commonly used bariatric surgery is laparoscopic or open Roux-en-Y gastrojejunal bypass (RYGB) and laparoscopic adjustable gastric banding. Other surgical techniques include vertical banded gastroplasty (Mason's operation), sleeve gastrectomy alone or with duodenal switch and biliopancreatic diversion $(7,8,10)$. Surgical treatment requires general anesthesia, which is a high-risk procedure in patients with a high-degree of obesity. Moreover, it should be kept in mind that surgery alters anatomy, which may lead to complications such as ulcers, fistulas, strictures, dumping syndrome, bleeding, anemia and diarrhea, among others (11).

Currently, research is focused on the development of alternative methods of obesity treatment that are not associated with high operative risk; therefore, the endoscopic treatment of obesity is of great interest. Endoscopy has an unquestionable role in the preoperative evaluation of patients undergoing bariatric surgery, and also in the assessment and treatment of its complications (11). In the future, the role of gastroenterologists in the treatment of obesity will increase due to the various endoscopic techniques that are currently being developed. To better understand the potential role for endoscopy in the treatment of obesity, one must understand that the mechanisms inducing gastric satiety are complex, and are related to gastric motor, endocrine and paracrine functions. It is known that several factors induce satiety such as gastric distention and accomodation, as well as hormones (cholecystokinin, bombesin, somatostatin, glucagon-like peptide-1 and ghrelin). Appetite control also involves other factors such as glycemia and hormones, with leptin, insulin, enterostatin and peptide YY also involved. Some hormones, such as cholecystokinin, peptide YY and ghrelin, also influence gastrointestinal motility and, through modification of gastric emptying, can cause early satiety and reduction of body weight in operated patients. The phenomenon of 'gastric accomodation' - the relaxation of the gastric wall in response to food intake - has been known for almost 100 years (12). Gastric accommodation consists of receptive relaxations induced by bolus deglutition and an adaptive relaxation to the increase of intragastric pressure due to food accumulation. The impairment of gastric accommodation appears to have implications in inducing satiety and the sensation of fullness $(13,14)$. It has been shown that obese patients have increased gastric accommodation, which positively correlates with the volume needed to suppress food intake (15). Concentric antrum contractions move gastric contents into the duodenum. In the

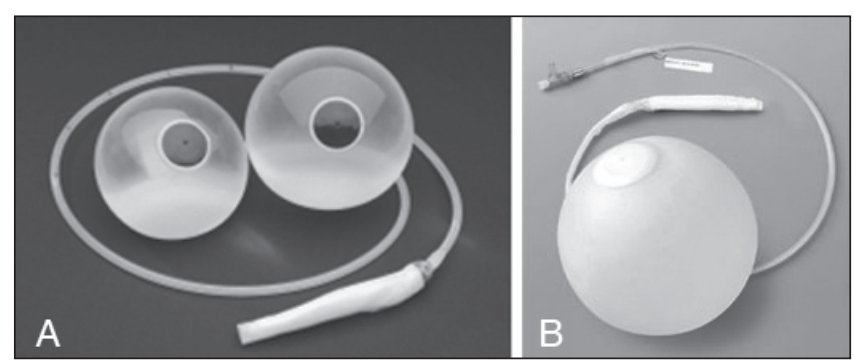

Figure 1) Intragastric ballons. A Saline-filled BioEnterics Intragastric Balloon (BioEnterics Corporation, USA). B The air-filled Heliosphere bag balloon (Helioscopie Medical Implants, France)

postprandial period, the early passage of solid food to the duodenum is prevented by contractions of the pylorus (16). The speed with which the stomach empties depends on the nature of the food, its osmolarity and chemical composition.

The present review discusses currently available endoscopic devices for the treatment of obesity.

\section{METHODS OF BARIATRIC ENDOTHERAPY}

Among endoscopic modalities in the treatment of obesity, the following methods are discussed: space-occupying devices, gastric capacity reduction methods, modifying gastric motor function methods and malabsorptive procedures (Table 1). In fact, among these methods, only space-occupying devices with intragastric balloons are widely used. Studies on humans or animals evaluating the use of the remaining methods are currently ongoing.

\section{Intragastric balloon}

The idea of using an endoscopically placed intragastric balloon for the treatment of obesity originated from the observation of psychiatric patients with gastric bezoars. This method was described for the first time in 1982 (17). Initially, balloons were made from gum and latex; however, because of their low resistance to damage from gastric acid, they deflated very quickly. In 1985, the US Food and Drug Administration approved a polyurethane air-filled balloon - the Garren-Edwards gastric bubble (American-Edwards Laboratories, USA) for the treatment of obesity as an adjunct to diet, behavioural therapy and exercise (18). The balloon was widely used in the US until 1988, when, despite the lack of controlled studies, more than 25,000 balloons were inserted (19). In the ensuing years, several studies were published, which concluded that treatment with this particular balloon was not superior to diet and behavioural therapy (20-22). Moreover, a high number of serious complications, such as gastric mucosal erosions (26\%), gastric ulcer (14\%) and small bowel obstruction $(2 \%)$, were reported $(23-25)$. Because of the significant adverse effects and the lack of supportive efficacy data, the Garren-Edwards gastric bubble was withdrawn from use. In the following years, other balloons (eg, the Taylor balloon and the Ballobes balloon) have also been evaluated in the treatment of obesity, but showed no additional benefit (26-28).

\section{BioEnterics Intragastric Balloon}

In 1987, an expert group defined the features of an 'ideal' intragastric balloon for the treatment of obesity, and constructed the BioEnterics Intragastric Balloon (BIB; BioEnterics Corporation, USA) $(29,30)$. The BIB is the most commonly used balloon for weight loss, and is made of a silicone elastomer and forms a sphere when inflated. The balloon has a self-sealing radiopaque valve that is connected to a catheter (Figure 1A). In the stomach, it can be maintained for six months (31). The balloon is filled with $400 \mathrm{~mL}$ to $700 \mathrm{~mL}$ of saline (usually $500 \mathrm{~mL}$ to $600 \mathrm{~mL}$ ). In one nonrandomized, retrospective study (32), it was suggested that a filling volume of $600 \mathrm{~mL}$ could provide greater weight loss at the time of BIB removal to that obtained with a filling volume of $500 \mathrm{~mL}(12.9 \mathrm{~kg}$ versus $8.6 \mathrm{~kg}$, respectively; $\mathrm{P}<0.05)$. 
Candidates for BIB placement should be aware that it is a temporary method to aid and promote weight loss. Indications for BIB therapy vary among studies and are based on criteria of BMI and the presence or absence of comorbidities. According to previous experience, the indications for BIB therapy are as follows: the primary indication is a BMI of $40 \mathrm{~kg} / \mathrm{m}^{2}$ or greater, with gastric balloon insertion serving as a pretreatment to bariatric surgery with the aim of reducing anesthesia risk and surgical complications; another indication is a BMI of between $27.0 \mathrm{~kg} / \mathrm{m}^{2}$ and $29.9 \mathrm{~kg} / \mathrm{m}^{2}$ in association with severe comorbidities (eg, insulin-dependent diabetes) that will likely improve with weight loss; gastric balloon treatment is also indicated in patients with a BMI of between $30 \mathrm{~kg} / \mathrm{m}^{2}$ and $34.9 \mathrm{~kg} / \mathrm{m}^{2}$ with comorbidities, or a BMI of between $35.0 \mathrm{~kg} / \mathrm{m}^{2}$ and $39.9 \mathrm{~kg} / \mathrm{m}^{2}$ without comorbidities (33); other indications for BIB are contraindications to bariatric surgery and lack of consent for surgical treatment. The 'BIB test' has been proposed as helpful to predict whether a gastric restrictive surgical procedure would be successful in particular patients (34). In a prospective study (35), this test was used to evaluate 40 patients who underwent BIB treatment followed by laparoscopic adjustable gastric banding. The final weight loss was higher in patients who underwent successful BIB therapy (defined as more than a $10 \%$ loss in baseline weight) than in patients with unsuccessful BIB therapy at 18 months (12.4 $\mathrm{kg}$ versus $9.0 \mathrm{~kg}$, respectively $[\mathrm{P}=0.03])$. In another study (36), bariatric surgery was performed most frequently in a group of patients who had successfully lost weight with the BIB. Finally, the insertion of an intragastric balloon may be predictive for testing the suitability of binge eaters for bariatric surgery (37). Conseqently, restrictive bariatric procedures should be considered for patients in whom BIB therapy leads to weight loss. By contrast, malabsorption procedures are offered to patients in whom BIB therapy does not result in weight loss. Absolute contraindications to the placement of BIB are the following: previous gastric surgery; hiatal hernia of $5 \mathrm{~cm}$ or greater; coagulation disorders; potentially bleeding lesion of the upper gastrointestinal tract; pregnancy, breastfeeding; severe liver disease; alcohol or drug addiction; and any contraindication to endoscopy. Relative contraindications include the following: previous abdominal surgery, hiatal hernia, esophagitis, Crohn's disease, nonsteroidal anti-inflammatory drug use and psychiatric disorders (33).

Once the indications for insertion of the gastric balloon are determined and none of the above contraindications are present, the insertion procedure can be performed under conscious sedation. Before insertion, the balloon is combined with a cylinder and is lubricated with xylocaine gel to facilitate passage through the upper esophageal sphincter. After balloon insertion into the stomach, it is positioned in the fundus under endoscopic control. The chuck is then removed from the catheter, and the balloon is filled with $500 \mathrm{~mL}$ to $700 \mathrm{~mL}$ of a physiological solution of saline mixed with $10 \mathrm{~mL}$ of methylene blue dye. In case of balloon deflation, the dye is absorbed and excreted by the kidneys causing green colouration of urine. The position of the balloon must then be verified. It is important to remember that propofol, which is used for sedation, can also cause green colouration of urine. After filling the balloon with saline, it is released by a short pull on the catheter. A valve prevents saline from flowing back. The BIB should be removed after a maximum of six months because, beyond this period, the risk of spontaneous balloon deflation significantly increases (33). The procedure for balloon removal is also performed under sedation. The balloon is punctured with a needle, it is then emptied of saline through the catheter and removed using forceps. Compared with previous types of balloons, the complications of BIB insertion occur less often $(33,38-41)$. The most common complications of BIB therapy are nausea and vomiting, which can persist for more than three weeks in $18 \%$ of patients. A randomized study (42), showed that tropisetron can be effective in reducing the incidence of vomiting in the first $24 \mathrm{~h}$ following BIB insertion. Adverse effects that persist for more than one week can be a rationale for balloon removal (38). Early endoscopic balloon removal (mainly because of balloon intolerance) occurs in $2.43 \%$ to $4.2 \%$ of cases $(33,41)$. The few deaths reported in the literature were due to gastric perforation in patients with a previous Nissen fundoplication and bronchoaspiration following BIB insertion (33). Other complications of BIB therapy include gastric ulcers and erosions, esophagitis, gastroesophageal reflux, abdominal pain, spontaneous balloon deflation, small bowel obstruction, gastric dilation and hypokalemia.

Based on previous experience, BIB has been shown to be an effective method of achieving short-term weight loss in approximately twothirds of patients $(33,40)$. The mean weight loss was $17.8 \mathrm{~kg}$, whereas higher absolute values were observed in higher BMI categories. BIB therapy improves comorbidities associated with obesity (eg, hypertension), reduces the number and the dose of hypotensive drugs, improves glycemic control and quality of life. The best candidates for BIB therapy are patients with a BMI of between $30 \mathrm{~kg} / \mathrm{m}^{2}$ and $39.9 \mathrm{~kg} / \mathrm{m}^{2}$, those who have failed to lose weight with other methods and in superobese patients in preparing for bariatric procedures $(33,43,44)$. Although the BIB has been used for more than 10 years, data regarding the success of weight maintenance for more than two years and the predictive factors for short-and long-term results success are still lacking (33). According to previous reports (45) and our experience, we believe that intragastric balloon deployment is a simple, effective, well tolerated and safe method to treat obesity.

\section{The Heliosphere Bag}

Adverse events, such nausea or vomiting, which may occur after BIB insertion and related to the weight of the balloon rather than to its size, were mitigated by the development of a new air-inflated balloon (intragastric air-filled balloon [Heliosphere Bag, Helioscopie Medical Implants, France) (Figure 1B) introduced into clinical practice in 2004. It weighs $30 \mathrm{~g}$ (in contrast to the BIB's weight of $500 \mathrm{~g}$ to $700 \mathrm{~g}$ ). Studies performed to date showed that the BAG balloon is safe and well tolerated. Its effect on weight loss appeared to be equivalent to other balloons. Twelve months after balloon removal, 30\% of the patients maintained a weight loss of greater than $10 \%$ (46). However, some technical difficulties occured during balloon removal, thus necessitating modification of the device's material (47).

\section{Semistationary antral balloon, silimed gastric balloon}

The semistationary antral balloon (SAB [JP Indústria Farmacéutica $\mathrm{SA}$, Brazil]) is also lighter than the BIB. The SAB is a pear-shaped silicone balloon that is filled with $150 \mathrm{~mL}$ to $180 \mathrm{~mL}$ of saline containing methylene blue. The conical end of the balloon enables it to dwell in the antrum. Additionally, at its caudal end, is a $30 \mathrm{~cm}$ duodenal stem with a $7 \mathrm{~g}$ metallic counterweight. The downstream peristaltic tractions on the counterweight facilitates anchorage of the balloon in the antrum. The ballon causes intermittent occlusion of the pylorus, prolongs gastric emptying and stimulates antral and duodenal satiety receptors. A pilot study of 26 patients (48) showed that a ballon implantated for a median period of four months caused a median weight reduction of $6.5 \mathrm{~kg}$ and was well tolerated due its small size. Four cases of balloon malfunction were observed (in one patient, the balloon leaked but remained in the stomach; in three patients, the balloon migrated distally). Four patients experienced nausea and mild gastric fullness during the first week. According to the authors of the study (48), complications resulted from balloon rupture, which could easily be prevented by improvements in design and the use of alternative materials. In another study (49), a new silimed gastric balloon (SGB) with a modified technique of insertion and removal, was used to improve safety and to fasten the procedure. The balloon is delicately rolled up inside a thin silicone sheath and is inserted endoscopically in the stomach. It is subsequently filled with saline solution using a tube with a polytetrafluoroethylene needle, which is connected to a self-sealing valve attached to the device shell. For removal, it is pulled out, held in an overtube and withdrawn as an entire system. Both procedures - placement and removal of the balloon - were simple and fast (mean time $9 \mathrm{~min}$ ), and were performed under sedation typically used for diagnostic endoscopy. Patients left the outpatient clinic less 


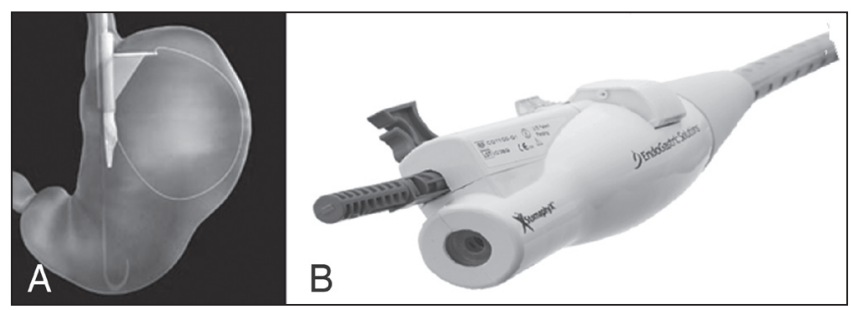

Figure 2) Gastric restrictive methods. A Transoral gastroplasty system. B The StomaphyX device (EndoGastric Solution, Inc, USA)

than $1 \mathrm{~h}$ after procedure completion. Procedure-related complications were not observed; however, early removal was required in $21 \%$ of cases. Preliminary data suggest that SGB is a safe and effective alternative method of obesity treatment in patients with the appropriate indications (49).

Additional controlled studies evaluating the efficacy and safety of $\mathrm{SAB}, \mathrm{BAG}$ and SGB demployment are needed before further use.

\section{Bezoars}

Currently, a device called the 'Butterfly' is being evaluated in experimental studies. It is a small, space-occupying device that consists of a double ribbon of polyester $18 \mathrm{~m}$ long and folded into loops. It is placed by pushing the loops into the stomach using a plastic tube and subsequently closed with a knot. The device is removed by cutting the deployment thread. In experimental animal studies (50), gastric ulcers were observed in $20 \%$ of subjects, and migration of bezoars was seen in almost one-third. The use of artificial bezoars is imminent and, ideally, should be easy to insert and remove, should not migrate and cause mucosal gastric damage, and should be safe and effective.

\section{GASTRIC RESTRICTIVE METHODS}

\section{Transoral gastroplasty}

Gastric restrictive procedures consist of gastroplasty through suturing, which capacitate gastric plication and partition. Manufacturers are competing with one another to design new transoral gastroplasty (TOGa) devices. One TOGa system (Satiety Inc, USA) is a specifically designed device that enables the creation of a stapled, restrictive pouch along the lesser curvature of the stomach (Figure 2A). Two pilot studies assessing the TOGa system in the treatment of obesity in humans have been published $(51,52)$. In both studies, this treatment method was effective with respect to weight loss, quality of life improvement and safety. Among the most commonly reported adverse events were the following: transient epigastric pain, nausea, vomiting, dysphagia, throat pain, esophagitis and superficial phlebitis. Most of these symptoms resolved spontaneously or with pharmacological treatment. Other serious complications were observed. The procedure is performed under general anesthesia with endotracheal intubation, with average procedure times exceeding $1 \mathrm{~h}$. After the procedure, patients were hospitalized overnight for observation and were instructed to consume a liquid diet exclusively within the first two weeks of the procedure. Before discharge, patients underwent $\mathrm{x}$-ray with gastrografin and barium swallow to visualize the new stomach anatomy and to verify the absence of any gastric leaks. At six months, endoscopy demonstrated a fully or partially persistent gastroplasty effect in all patients. Additionally, one study (51) reported improvement of the comorbidities associated with obesity. Hemoglobin A1c levels decreased in six of seven diabetic patients. Reductions in hypertension and improvement of lipid profile were also noted $(51,52)$. Although this method appears to be an effective and safe treatment for obesity, additional multicentre studies are necessary before its widespread use is implemented.

\section{StomaphyX}

StomaphyX (EndoGastric Solution Inc, USA) is another incision-less transoral fastening device used for tissue plications. This device enables suctioning of stomach tissue, fastening tissue folds and suturing (Figure 2B). Usually, multiple folding performed using this device results in a reduction in the size of the stomach pouch and slows the emptying of stomach contents into the small intestine, which results in earlier satiety. In 2007, the US Food and Drug Administration approved the StomaphyX procedure in patients after bariatric surgery who never achieved adequate weight loss or regained weight after the initial weight loss. Furthermore, the StomaphyX procedure has been successfully used for pouch and anastomosis volume reduction, and for management of gastric leaks that developed after revisions of RYGB in two patients. In these cases, the procedure lasted approximately $30 \mathrm{~min}$ and was performed without complications. Previous experience demonstrated that this method is safe and atraumatic (53-55). Additional studies are assessing the utility of StomaphyX as a primary method of obesity treatment.

Newer, more advanced devices for transoral gastroplasty will undoubtedly be developed. These devices should be very flexible and should enable full-thickness plication. The procedure should be performed in a small area in a short time, and under usual sedation.

\section{Botulinum toxin}

Great expectations were associated with the use of intragastric injection of botulinum toxin, which hypothetically delays gastric emptying and inhibits ghrelin secretion - the main source of which is the gastric fundus. Plasma levels of ghrelin increase during periods of fasting and decrease after a meal. This hormone accelerates gastric emptying and also stimulates gastric motility during fasting (56). In 2000, Gui et al (57) published results of a pioneering study, in which they showed that intramuscular injections of botulinum toxin in the gastric wall of normal-weight rats significantly reduced their food intake and body weight. In 2005, these results were confirmed in obese rats, in which significant delay of gastric emptying was observed after botulinum toxin injection (58). In 2003, Rollnik at al (59) reported that four months after botulinum toxin injection into the antrum of the stomach, an obese man lost $9 \mathrm{~kg}$ and his daily caloric intake decreased by approximately $32.5 \%$. A study published two years later (60) showed that intragastric injection of botulinum toxin was safe and well tolerated. The published studies (60-66), however, have reported conflicting results. One study performed by an Italian group (64) reported a delay in gastric emptying, early satiety and body weight reduction. In analyzed studies (60-65), varying doses of butulinum toxin (from 100 IU to $300 \mathrm{IU}$ ) were used; however, perhaps more important than the dose of toxin, was the method of its application. In one study (64), the toxin was injected both into the antrum and the gastric fundus. In the other studies, it was only injected in the antrum, which likely explains the differences in results that were observed (66). Additional studies are needed to assess the role of botulium toxin in the treatment of obesity. The use of botulinum toxin in the treatment of obesity in the future is unclear because the drug is expensive; furthermore, it will be difficult to perform studies with a large number of patients. Athough the use of botulium toxin to reduce body weight has yet to be definitively proven, the limitation of the drug is the short duration of its effect - the injections must be repeated, thereby making the treatment troublesome for patients and increases cost.

\section{Duodenal-jejunal bypass sleeve}

Bariatric surgical procedures, such as RYGB, lead to weight loss and improve metabolic control through various mechanisms: isolation of the gastric cardia; exclusion of the distal stomach; exclusion of the duodenum and proximal jejunum; exposure of the distal jejunum to undigested nutrients; and partial vagotomy. In recent years, new endoluminal bypass procedures developed in animal models have enabled two components of RYGB: exclusion of the duodenum and proximal jejunum and exposure of the distal jejunum to undigested nutrients. 
Therefore, the duodenal-jejunal bypass sleeve (DJBS [Endobarrier, GI Dynamics, USA]) is an endoscopic method used to reduce jejunal absorption. The bypass is a flexible, nutrient-impermeable $60 \mathrm{~cm}$ sleeve that is anchored in the duodenal bulb and extended into the proximal jejunum (Figure 3). The catheter-based delivery system is introduced into the duodenal bulb over the guide wire and deployed to the jejunum using dynamic fluoroscopy. Once the sleeve is fully deployed, the anchor is deployed to form the capsule. The anchor - the distal tip of sleeve - is a self-expanding $5.5 \mathrm{~cm}$ nitinol stent that enables fixation within the duodenal bulb. After placement, the sleeve is maintained for 12 weeks, after which time, it is removed endoscopically. The bypass placed in the proximal jejunum prevents the mixing of digestive enzymes and gastric contents. The ingested nutrients pass from the pylorus directly into and through the lumen of the sleeve without any contact with digestive enzymes and bile that flow outside of the device. Therefore, the bypass prevents contact between nutrient-rich chyme and mucosa in the proximal intestine. This endoscopic device enables the bypass of dysfunctional digestive and absorptive processes. Since 2007, when the experts group defined the features of the duodenal-jejunal bypass sleeve, results of several studies on animals and humans were published, in which it was shown that this method leads to weight loss and is safe (67-71). In one prospective study, the bypass was endoscopically inserted and maintained for 12 weeks in 12 patients, with no serious complications. Procedure-related adverse events (during device removal) occurred in two patients: oral-pharyngeal and esophageal mucosal tear. Moreover, in the follow-up period, mostly during the first week, several self-limited and mild-to-moderate adverse events including abdominal pain, nausea, vomitting and implant site inflammation (71 in 12 patients), were observed. Only two of these 12 patients required early removal of the implant due to excessive abdominal pain and discomfort. The average weight loss was $10.2 \mathrm{~kg}$ and the average baseline decrease in BMI was $3.8 \mathrm{~kg} / \mathrm{m}^{2}(70)$. In another randomized, prospective study (71), the influence of DJBS and low-calorie diet for preoperative weight loss in bariatric surgery was compared. At 12 weeks, significantly higher body weight reduction was observed in the DJBS group (22\%) than in the group treated only with diet modification (5\%). However, complications after DJBS placement were observed in 20\% of patients (five of 25 patients). Upper gastrointestinal bleeding occurred in three patients, stent migration occurred in one patient and sleeve obstruction in one patient. The bleeding that was observed at a mean of 13.8 days postimplant did not require blood transfusion. Presently, the procedure is performed under general anesthesia; however, in the future, it will probably be performed under usual sedation, which is important for obese patients who are at high risk in procedures requiring general anesthesia. The role of DJBS in the treatment of obesity has yet to be clearly defined. More data regarding the efficacy and safety of this promising method are being collected (69).

\section{Intragastric prothesis}

The Adjustable Totally Implantable Intragastric Prothesis (ATIIPEndogast, Districlass Medical SA, France) is a new, minimally invasive

\section{REFERENCES}

1. Babińska Z, Bandosz P, Zdrojewski T, Wyrzykowski B.

[Epidemiologia otyłosci i otyłosci brzusznej w Polsce, Europie

Zachodniej i USA.] Kardiologia w Praktyce 2004;5:3-7.

2. Ogden CL, Carroll MD, Curtin LR, McDowell MA, Tabak CJ,

Flegal KM. Prevalence of overweight and obesity in the United States, 1999-2004. JAMA 2006;295:1549-55.

3. Centers for Disease Control and Prevenion. NCHC Health E-stats. $<$ http://www.cdc.gov/nchs/data/hestat/overweight/overweight_adult. $\mathrm{htm} />$ (Accessed on December 23, 2009).

4. El-Serag HB. Obesity and disease of the esophagus and colon. Gastroenterol Clin North Am 2005;34:63-82.

5. Clinical guidelines on the identification, evaluation, and treatment of overweight and obesity in adults - the evidence report.

National Institutes of Health Obes Res 1998;6:S51-S209.

6. Schneider BE, Mun EC. Surgical management of morbid obesity. Diabetes Care 2005;28:475-80.

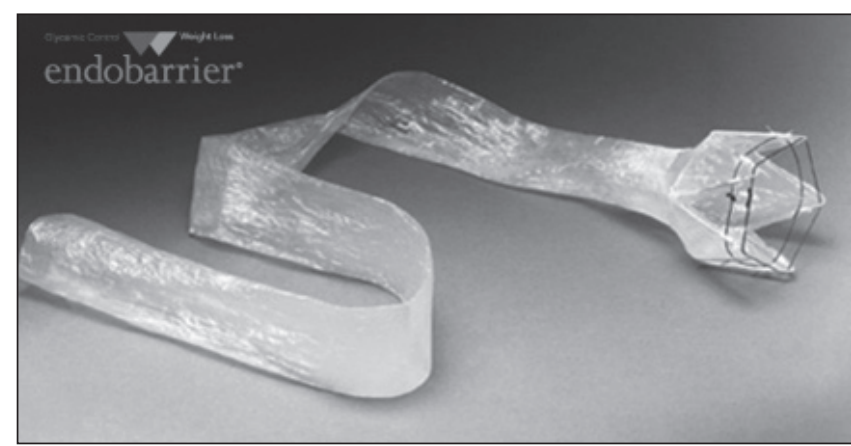

Figure 3) Endobarrier (GI Dynamics Inc, USA) duodenal-jejunal bypass sleeve

technique using surgical and endoscopic procedures for the treatment of obesity. The device is inserted in the gastric corpus-fundus area using a method similar to percutaneus endoscopic gastrostomy. The two main principles in this method are the permanent presence of an air-filled prothesis inside the stomach and the fixation of the stomach to the abdominal wall. The aim of the ATIIP-Endogast device is to induce early satiety and a reduction in body weight. Proximal gastric positioning has an effect on gastric accomodation, electrical activity and neurohormonal mechanisms. Preliminary study results (72) suggest that the ATIIP-Endogast device is feasible, reproducible, safe and is associated with a low risk of complications, especially for obese patients older than 60 years of age, and superobese patients with a BMI of greater than $50 \mathrm{~kg} / \mathrm{m}^{2}$. The ATIIP is a promising weight-reduction method; however, there is concern regarding local infection related to percutaneous endoscopic gastrostomy placement.

\section{SUMMARY}

Recently, clinical research has been focused on the development of different endoscopic devices for weight loss, and has yielded promising results. Endoscopic treatment may constitute one of the essential components of the complex management of obese patients. Restrictive methods may be a supplementary therapy or may be used as a bridge to more durable, definitive procedures. The restrictive methods can also provide excellent long-term results and avoid complications related to the presence of a foreign body in the stomach. However, more data regarding the efficacy and safety of endoscopic devices are necessary before they are widely used in the future. In addition to the development of new, minimally invasive endoscopic techniques, gastroenterologists will play a greater and, perhaps the central, role in the management of obese patients.

DISCLOSURES: The authors have no financial disclosures or conflicts of interest to declare.

7. Bult MJ, van Dalen T, Muller AF. Surgical treatment of obesity. Eur J Endocrinol 2008;158:135-45.

8. Santry HP, Gillen DL, Lauderdale DS. Trends in bariatric surgical procedures. JAMA 2005;294:1909-17.

9. Griffen WO Jr, Bivins BA, Bell RM. The decline and fall of the jejunoileal bypass. Surg Gynecol Obstet 1983;157:301-8.

10. Buchwald H, Williams SE. Bariatric surgery worldwide 2003. Obes Surg 2004;14:1157-64.

11. Anderson MA, Gan SI, Fanelli RD, et al; ASGE Standards of Practice Committee. Role of endoscopy in the bariatric surgery patients. Gastrointest Endosc 2008;68:1-10.

12. Cannon WB, Washburn AL. An explanation of hunger. 1911. Obes Res 1993;1:494-500.

13. Mundt MW, Hausken T, Smout AJ, et al. Relationships between gastric accommodation and gastrointestinal sensations in healthy volunteers. A study using the barostat technique and two- and three-dimensional ultrasonography. Dig Dis Sci 2005;50:1654-60. 
14. Kindt S, Tack J. Impaired gastric accommodation and its role in dyspepsia. Gut 2006;55:1685-91.

15. Geliebter A. Gastric distension and gastric capacity in relation to food intake in humans. Physiol Behav 1988;44:665-8.

16. Quigley EM. Gastroduodenal motility. Curr Opin Gastroenterol 2000;16:479-88

17. Nieben OG, Harboe H. Intragastric balloon as an artificial bezoar for treatment of obesity. Lancet 1982;1:198-9.

18. Dillon JG, Hughes MK. Degradation of five polyurethane gastric bubbles following in vivo use: SEC, ATR-IR and DSC studies. Biomaterials 1992;13:240-8.

19. Geliebter A, Melton PM, Gage D, McCray RS, Hashim SA. Gastric balloon to treat obesity: A double-blind study in nondieting subjects. Am J Clin Nutr 1990;51:584-8.

20. Hogan RB, Johnston JH, Long BW, et al. A double-blind, randomized, sham-controlled trial of the gastric bubble for obesity. Gastrointest Endosc 1989;35:381-5.

21. Kirby DF, Wade JB, Mills PR, et al. A prospective assessment of the Garren-Edwards gastric bubble and bariatric surgery in the treatment of morbid obesity. Am Surg 1990;56:575-80.

22. Meshkinpour H, Hsu D, Farivar S. Effect of gastric bubble as a weight reduction device: A controlled, crossover study. Gastroenterology 1988;95:589-92.

23. Benjamin SB, Maher KA. Double-blind controlled trial of the Garren-Edwards gastric bubble: An adjunctive treatment for exogenous obesity. Gastroenterology 1988;95:581-8.

24. Benjamin SB. Small bowel obstruction and the Garren-Edwards gastric bubble: An iatrogenic bezoar. Gastrointest Endosc 1988;34:463-7.

25. Ulicny KS Jr, Goldberg SJ, Harper WJ, Korelitz JL, Podore PC, Fegelman RH. Surgical complication of the Garren-Edwards gastric bubble. Surg Gynecol Obstet 1988;166:535-40.

26. Marshall JB, Schreiber H, Kolozsi W, et al. A prospective, multi-center clinical trial of the Taylor intragastric balloon for the treatment of morbid obesity. Am J Gastroenterol 1990;85:833-7.

27. Mathus-Vliegen EM, Tytgat GN, Veldhuyzen-Offermans EA. Intragastric balloon in the treatment of super-morbid obesity. Double-blind, sham-controlled, crossover evaluation of 500 milliliter balloon. Gastroenterology 1990;99:362-9.

28. Geliebter A, Melton PM, McCray RS, et al. Clinical trial of silicone-rubber gastric balloon to treat obesity. Int J Obes 1991;15:259-66.

29. Schapiro M, Benjamin S, Blackburn G, et al. Obesity and the gastric balloon: A comprehensive workshop. Gastrointest Endosc 1987;33:323-7.

30. Galloro G, De Palma GD, Catanzano C, et al. Preliminary endoscopic technical report of a new silicone intragastric balloon in the treatment of morbid obesity. Obes Surg 1999;9:68-71.

31. Totté E, Hendrickx L, Pauwels M, Van Hee R. Weight reduction by means of intragastric device: Experience with the bioenterics intragastric balloon. Obes Surg 2001;11:519-23.

32. Roman S, Napoléon B, Mion F, et al. Intragastric balloon for "non-morbid" obesity: A retrospective evaluation of tolerance and efficacy. Obes Surg 2004;14:539-44.

33. Dumonceau JM. Evidence-based review of the Bioenterics intragastric balloon for weight loss. Obes Surg 2008;18:1611-7.

34. Loffredo A, Cappuccio M, De Luca M, et al. Three years experience with the new intragastric balloon, and a preoperative test for success with restrictive surgery. Obes Surg 2001;11:330-3.

35. de Goederen-van der Meij S, Pierik RG, Oudkerk Pool M, Gouma DJ, Mathus-Vliegen LM. Six months of balloon treatment does not predict the success of gastric banding. Obes Surg 2007;17:88-94.

36. Melissas J, Mouzas J, Filis D, et al. The intragastric balloon-smoothing the path to bariatric surgery. Obes Surg 2006;16:897-902.

37. Puglisi F, Antonucci N, Capuano P, et al. Intragastric balloon and binge eaters. Obes Surg 2007;17:504-9.

38. Doldi SB, Michaletto G, Perrini MN, Rapetti R. Intragastric balloon another option for treatment of obesity and morbid obesity. Hepatogastroenterology 2004;51:294-7.

39. Laurent B, Charles D, Laurent M. Covered gastric perforation by the BioEnterics Intragastric Balloon. J Clin Gastroenterol 2001;33:344-5.

40. Pretolesi F, Redaelli G, Papagni L, Derchi LE. Intragastric balloon for morbid obesity causing chronic gastric dilatation. Eur Radiol 2001;11:588-9.
41. Imaz I, Martínez-Cervell C, García-Alvarez EE, Sendra-Gutiérrez JM, González-Enríquez J. Safety and effectiveness of the intragastric balloon for obesity. A meta-analysis. Obes Surg 2008;18:841-6.

42. Van Hee R, Van Wiemeersch S, Lasters B, Weyler J. Use of antiemetics after intragastric balloon placement: Experience with three different drug treatments. Obes Surg 2003;13:932-7.

43. Konopko-Zubrzycka M, Baniukiewicz A, Wróblewski E, et al. The effect of intragastric balloon on plasma ghrelin, leptin, and adiponectin levels in patients with morbid obesity. J Clin Endocrinol Metab 2009;94:1644-9.

44. Göttig S, Daskalakis M, Weiner S, Weiner RA. Analysis of safety and efficacy of intragastric balloon in extremely obese patients. Obes Surg 2009;19:677-83.

45. Mui WL, Ng EK, Tsung BY, Lam CH, Yung MY. Impact on obesity-related illnesses and quality of life following intragastric balloon. Obes Surg 2008;20:1128-32.

46. Mion F, Gincul R, Roman S, et al. Tolerance and efficacy of an air-filled balloon in non-morbidly obese patients: Results of a prospective multicenter study. Obes Surg 2007;17:764-9.

47. Trande P, Mussetto A, Mirante VG, et al. Efficacy, tolerance and safety of new intragastric air-filled balloon (Heliosphere BAG) for obesity: The experience of 17 cases. Obes Surg 2010;20:1227-30.

48. Lopasso FP, Sakai P, Gazi BM, et al. A pilot study to evaluate the safety, tolerance, and efficacy of a novel stationary antral balloon (SAB) for obesity. J Clin Gastroenterol 2008;42:48-53.

49. Carvalho GL, Barros CB, Okazaki M, et al. An improved intragastric balloon procedure using a new balloon: Preliminary analysis of safety and efficiency. Obes Surg 2009;19:237-42.

50. Hashiba K, Brasil HA, Wada AM. Experimental study an alternative endoscopic method for the treatment of obesity: The butterfly technique. Gastrointest Endosc 2001;53:AB112.

51. Devière J, Ojeda Valdes G, Cuevas Herrera L, et al. Safety, feasibility and weight loss after transoral gastroplasty: First human multicenter study. Surg Endosc 2008;22:589-98.

52. Moreno C, Closset J, Dugardeyn S, et al. Transoral gastroplasty is safe, feasible, and induces significant weight loss in morbidly obese patients: Results of the second human pilot study. Endoscopy 2008;40:406-13.

53. Higa KD, Boone K, Nimeri A, Tercero F, Jackson A, Khan A. Gastric bypass: Increased restriction for poor weight loss. Surg Endosc 2007;21:1922-3.

54. Nguyen NT. Reoperations and revisions in bariatric surgery. Surg Endosc 2007;21:1907-8.

55. Overcash WT. Natural orifice surgery (NOS) using StomaphyX for repair of gastric leaks after bariatric revisions. Obes Surg 2008;18:882-5.

56. Peeters TL. Potential of ghrelin as a therapeutic approach for gastrointestinal motility disorders. Curr Opin Pharmacol 2006;6:553-8.

57. Gui D, De Gaetano A, Spada PL, Viggiano A, Cassetta E, Albanese A. Botulinum toxin injected in the gastric wall reduces body weight and food intake in rats. Aliment Pharmacol Ther 2000;14:829-34.

58. Coskun H, Duran Y, Dilege E, Mihmanli M, Seymen H, Demirkol MO. Effect on gastric emptying and weight reduction of botulinum toxin-A injection into the gastric antral layer: An experimental study in the obese rat model. Obes Surg 2005;15:1137-43.

59. Rollnik JD, Meier PN, Manns MP, Göke M. Antral injections of botulinum a toxin for the treatment of obesity. Ann Intern Med 2003;138:359-60.

60. García-Compean D, Mendoza-Fuerte E, Martínez JA, Villarreal I, Maldonado H. Endoscopic injection of botulinum toxin in the gastric antrum for the treatment of obesity. Results of a pilot study. Gastroenterol Clin Biol 2005;29:789-91.

61. Albani G, Petroni ML, Mauro A, et al. Safety and efficacy of therapy with botulinum toxin in obesity: A pilot study. J Gastroenterol 2005;40:833-5.

62. Júnior AC, Savassi-Rocha PR, Coelho LG, et al. Botulinum A toxin injected into the gastric wall for the treatment of class III obesity: A pilot study. Obes Surg 2006;16:335-43.

63. Gui D, Mingrone G, Valenza V, et al. Effect of botulinum toxin antral injection on gastric emptying and weight reduction in obese patients: A pilot study. Aliment Pharmacol Ther 2006;23:675-80.

64. Foschi D, Corsi F, Lazzaroni M, et al. Treatment of morbid obesity by intraparietogastric administration of botulinum toxin: A randomized, double-blind, controlled study. Int J Obes (Lond) 2007;31:707-12. 
65. Mittermair R, Keller C, Geibel J. Intragastric injection of botulinum toxin A for the treatment of obesity. Obes Surg 2007;17:732-6.

66. Garcia-Compean D, Maldonado Garza H. Intragastric injection of botulinum toxin for the treatment of obesity. Where are we? World J Gastroenterol 2008;14:1805-9.

67. Aguirre V, Stylopoulos N, Grinbaum R, Davis PJ, Levine AH, Kaplan LM. An indwelling endoluminal sleeve induces substantial weight loss and improvements of glucose homeostasis in rats with diet-induced obesity. Digestive Disease Week, Washingon, DC, May 19 to 24, 2007. <http://www.gidynamics.com/mediapublications-abstracts.php> (Accessed on May 6, 2011).

68. Aguirre V, Stylopoulos N, Grinbaum R, Kaplan LM. An endoluminal sleeve induces substantial weight loss and normalizes glucose homeostasis in rats with diet-induced obesity. Obesity 2008;16:2585-92.
69. Gersin KS, Keller JE, Stefanidis D, et al. Duodenal-jejunal bypass sleeve: A totally endoscopic device for the treatment of morbid obesity. Surg Innov 2007;14:275-8.

70. Rodriguez-Grunert L, Galvao Neto MP, Alamo M, Ramos AC, Baez PB, Tarnoff M. First human experience with endoscopically delivered and retrieved duodenal-jejunal bypass sleeve. Surg Obes Relat Dis 2008;4:55-9.

71. Tarnoff M, Rodriguez L, Escalona A, et al. Open label, prospective, randomized controlled trial of an endoscopic duodenal-jejunal bypass sleeve versus low calorie diet for pre-operative weight loss in bariatric surgery. Surg Endosc 2009;23:650-6.

72. Gaggiotti G, Tack J, Garrido AB Jr, Palau M, Cappelluti G, Di Matteo F. Adjustable totally implantable intragastric prosthesis (ATIIP)-Endogast for treatment of morbid obesity: One-year follow-up of a multicenter prospective clinical survey. Obes Surg 2007;17:949-56. 


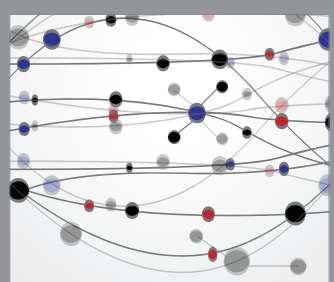

The Scientific World Journal
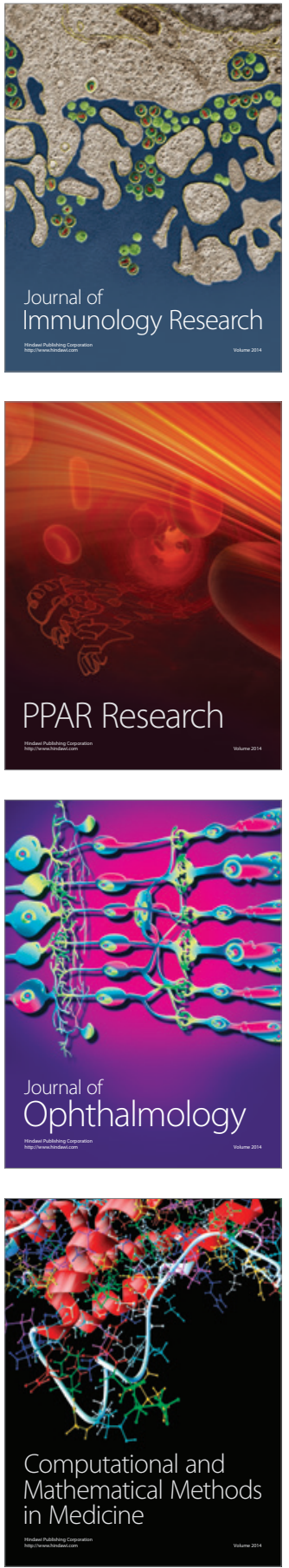

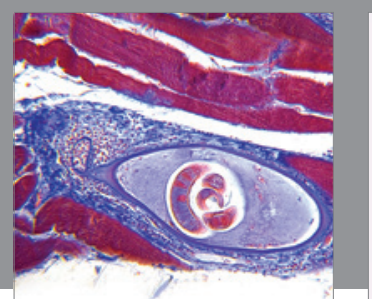

Gastroenterology Research and Practice

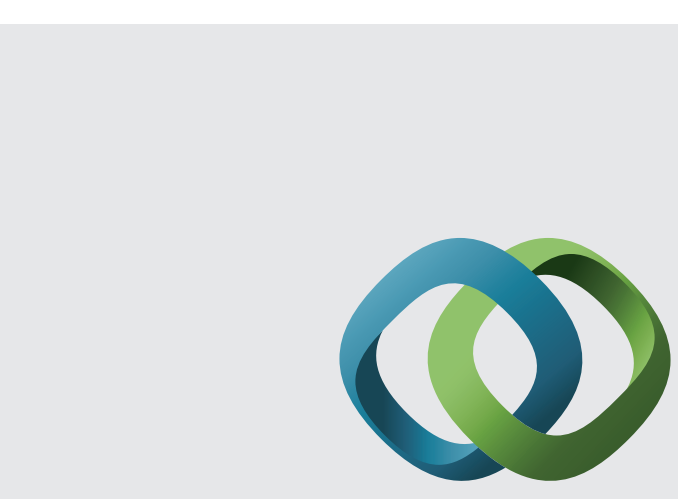

\section{Hindawi}

Submit your manuscripts at

http://www.hindawi.com
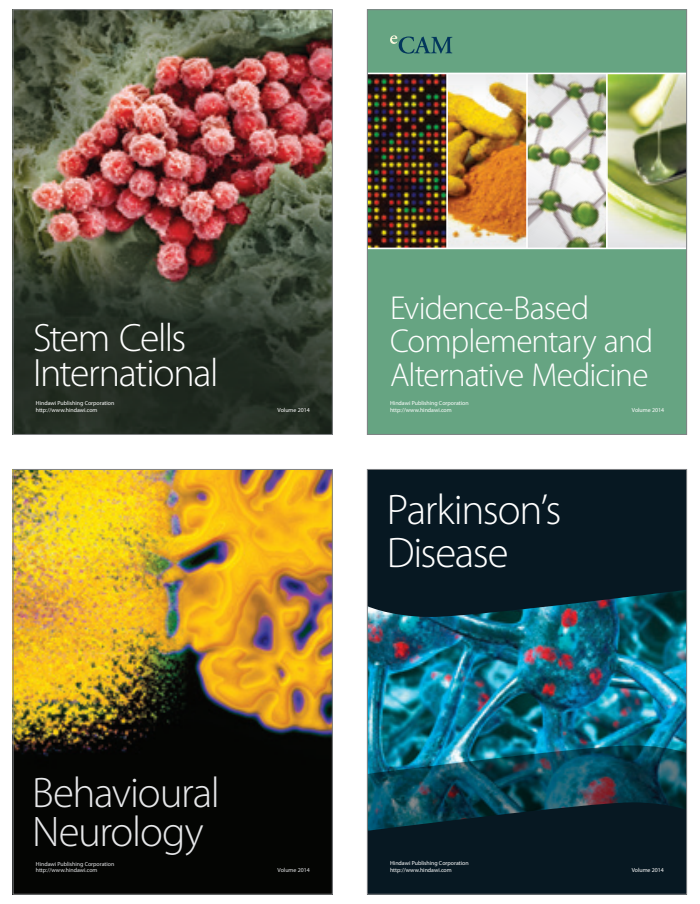
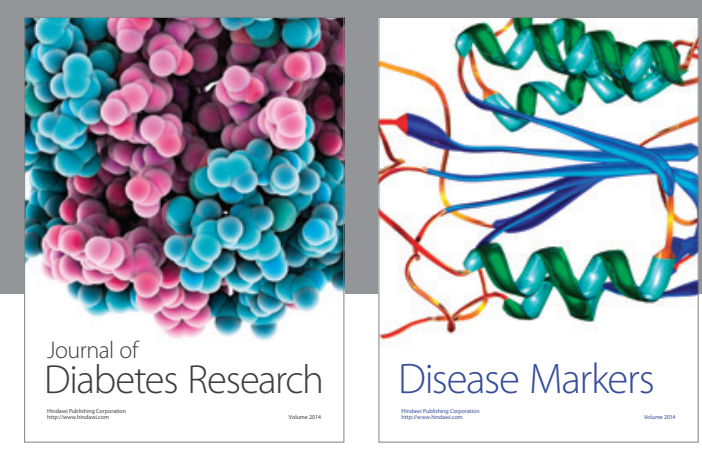

Disease Markers
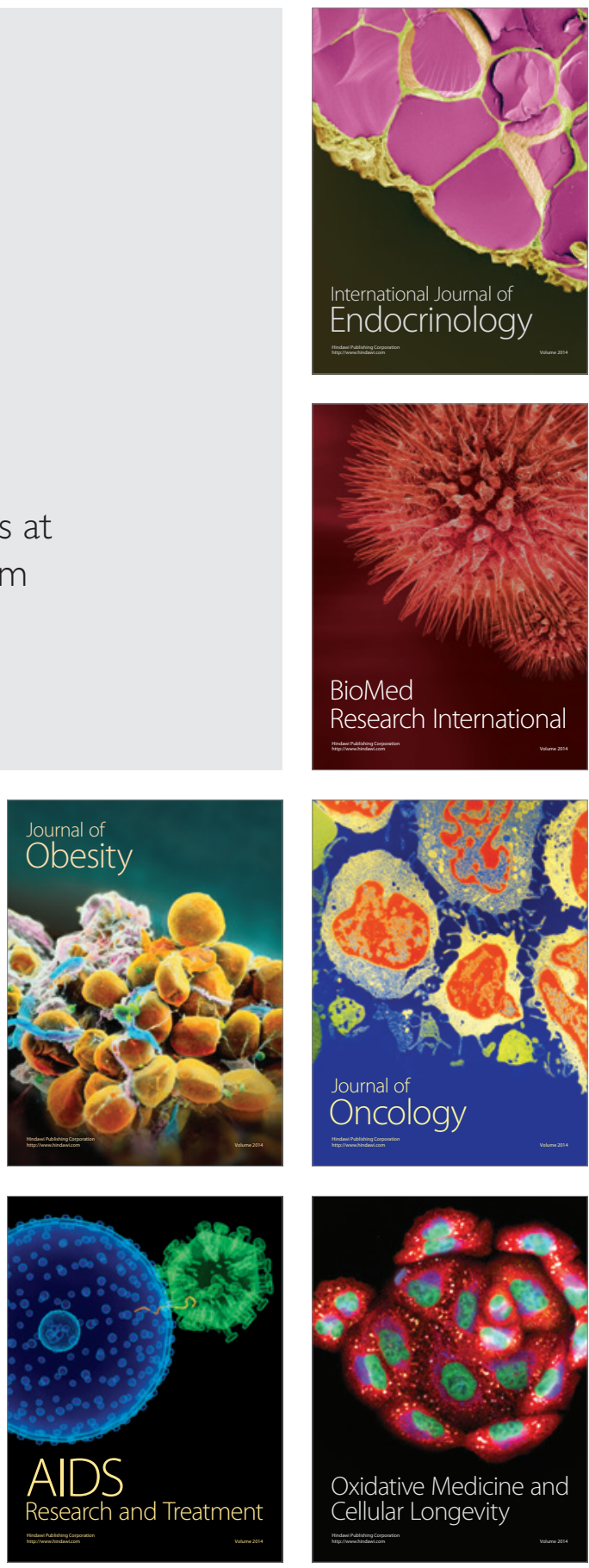